\title{
Demographic and clinical characteristics of severe Covid-19 infections: a cross-sectional study from Mashhad University of Medical Sciences, Iran
}

Ladan Goshayeshi ${ }^{1,2 \dagger}$, Mina Akbari Rad ${ }^{3 \dagger}$, Robert Bergquist ${ }^{4,5}$, Abolghasem Allahyari ${ }^{3}$, Kamila Hashemzadeh ${ }^{6}$, MUMS Covid-19 Research Team and Benyamin Hoseini ${ }^{78^{*}}$ (i)

\begin{abstract}
Background: Coronavirus Disease 2019 (Covid-19) is expanding worldwide. The characteristics of this infection in patients varies from country to country. To move forward, clinical data on infected patients are needed. Here, we report a comparison between fatalities and recovery of patients with severe Covid-19, based on demographic and clinical characteristics.

Methods: Between 5 March and 12 May 2020 in Mashhad, Iran, 1278 of 4000 suspected Covid-19 patients were confirmed positive by real-time reverse-transcriptase-polymerase-chain-reaction assay of upper respiratory specimens. We compared the demographic, exposure history and clinical symptoms of 925 survivors and 353 fatal cases with confirmed disease.

Results: Mean (SD) age for all confirmed patients was 56.9 (18.7) years, 67.1 (15.9) years in fatal cases and 53.0 (18.3) years in survivors. Multivariate logistic regression analysis showed that the outcome of patients was associated with age (odds ratio $=1.049, P=0.0001,95 \% \mathrm{Cl}=1.040-1.057$ ). Despite a high burden of Covid-19 infections in the 30-39 and 40-49 year age groups, most of these ( 89.6 and $87.2 \%$, respectively) recovered. The median (IQR) duration of hospitalization was 9.0 (6.0-14.0) days. The most prevalent co-morbidities were cardiovascular disorders (21\%) and diabetes (16.3\%). Dyspnoea (72.7\%), cough (68.1\%) and fever (63.8\%) were the most frequent clinical symptoms. Healthcare workers, of whom two (3\%) died, comprised 5.2\% of infected cases. Combination antiviral and antibiotic therapy was used in $43.0 \%$ of cases.
\end{abstract}

\footnotetext{
* Correspondence: Hoseinib1@nums.ac.ir

†Ladan Goshayeshi and Mina Akbari Rad contributed equally as joint lead authors.

${ }^{7}$ Department of Health Information Technology, Neyshabur University of Medical Sciences, Neyshabur, Iran

${ }^{8}$ Pharmaceutical Research Center, Mashhad University of Medical Sciences, Mashhad, Iran

Full list of author information is available at the end of the article
}

\section{$\triangle B M C$}

(c) The Author(s). 2021 Open Access This article is licensed under a Creative Commons Attribution 4.0 International License, which permits use, sharing, adaptation, distribution and reproduction in any medium or format, as long as you give appropriate credit to the original author(s) and the source, provide a link to the Creative Commons licence, and indicate if changes were made. The images or other third party material in this article are included in the article's Creative Commons licence, unless indicated otherwise in a credit line to the material. If material is not included in the article's Creative Commons licence and your intended use is not permitted by statutory regulation or exceeds the permitted use, you will need to obtain permission directly from the copyright holder. To view a copy of this licence, visit http://creativecommons.org/licenses/by/4.0/ The Creative Commons Public Domain Dedication waiver (http://creativecommons.org/publicdomain/zero/1.0/) applies to the data made available in this article, unless otherwise stated in a credit line to the data. 
Conclusions: The characteristics of severe Covid-19 varied substantially between fatal cases and survivors, with diabetes and cardiovascular disorders the most prevalent co-morbidities. In contrast to other studies, there were a higher number of fatalities in younger patients in our setting.

Keywords: COVID-19, SARS-COV-2, Epidemiological characteristics, Symptoms, Iran

\section{Background}

In late 2019, the city of Wuhan, Hubei Province, China became the centre of an unusual pneumonia-like disease of an unknown cause [1-3]. In January 2020, Chinese scientists realized that this condition was caused by a novel Coronavirus, first called 2019-nCOV $[4,5]$. On January 7, 2020, scientists isolated this novel type of Coronavirus from the sputum of these patients, which was on February 11, 2020 classified as Severe Acute Respiratory Syndrome Coronavirus type two (SARS-CoV2) by the International Committee on Taxonomy of Viruses $[5,6]$. On the same date, the World Health Organization (WHO) named the disease caused by this virus coronavirus disease 2019 (Covid-19) in the International Classification of Diseases [5]. As of March 11, 2020 when the Covid-19 outbreak had spread worldwide and reached 118,319 confirmed cases and 4292 confirmed deaths, WHO declared it a global pandemic [710]. The initial source of Covid-19 is still unknown, but it is now confirmed that the first known case of this disease was linked to the Huanan seafood market of Wuhan City, which was closed on January 1, 2020 to control the situation $[1,11]$.

SARS-CoV-2 is a member of the Coronaviridae family that consists of a single-stranded positive-sense RNA genome [1]. Although, there are four endemic human coronaviruses as well (CoV-HKU1, CoV-NL63, CoV-229E and CoV-OC43), so far, two notable human infections by viruses related to Coronaviridae family are known: the Severe Acute Respiratory Syndrome (SARS), caused by SARS-CoV, which emerged in China in 2002 and spread across 37 countries, and the Middle-East Respiratory Syndrome (MERS), caused by MERS-CoV, which was first seen in Saudi Arabia in 2012 [1]. There were two separate outbreaks of SARS in the period 2002-2004, while cases of MERS still occur though only rarely [12]. SARS-COV-2 is genetically related to SARS-CoV with both of them being beta- coronaviruses $[4,13]$.

The clinical manifestation of Covid-19 varies from asymptomatic infection to severe viral pneumonia with multisystem failure leading to death $[2,5,14,15]$. The most common clinical manifestations include, but are not limited to, fever, non-productive cough, myalgia, fatigue and dyspnoea. Chest radiography shows bilateral lung infiltrations indicative of pneumonia and laboratory indices include increased erythrocyte sedimentation rate and C-Reactive protein and, lymphopenia $[5,16]$. In severe cases, acute respiratory distress syndrome, acute cardiac and kidney injury and shock can occur, which may lead to irreversible organ failure and death [16-19].

Severe illness usually begins approximately 1 week after the onset of symptoms. Dyspnoea is the most common symptom of severe disease and is often accompanied by hypoxemia [5, 16]. Severe Covid-19 in adults is defined as dyspnoea, a respiratory rate of 30 or more breaths per minute, a blood oxygen saturation of $93 \%$ or less, a ratio of the partial pressure of arterial oxygen to the fraction of inspired oxygen (Pao2:Fio2) of less than $300 \mathrm{mmHg}$, or infiltrates in more than $50 \%$ of the lung field within 24 to $48 \mathrm{~h}$ from the onset of symptoms [20]. Patients with severe Covid-19 should be hospitalized for careful monitoring.

By May 16, 2020, there were 4,602,900 confirmed cases with 307,135 confirmed deaths globally, translating into a case fatality rate (CFR) of $6.67 \%$. At this date, there were 116,635 confirmed cases with 6902 deaths in Iran resulting in the same CFR (WHO daily report). We aimed to describe the characteristics of patients with Covid-19 in Razavi Khorasan, a province in Iran which has a population of 6.5 million. Herein, we report demographic and clinical characteristics of patients with severe Covid-19 in Mashhad, the second largest city in Iran and capital of Razavi Khorasan.

\section{Materials and methods}

We undertook a retrospective cross-sectional study of consecutive Covid-19 patients diagnosed between 5 March and 12 May 2020 in Mashhad, Iran (see Supplementary file included the completed checklist of STROBE Statement). Data were collated by the centre for Diseases Prevention and Control of Mashhad University of Medical Sciences. We received initial data from this centre and sought the missing data from patients' medical records. The cases would be excluded if their health outcome was unknown. In our study, $94 \%$ of the cases were inpatients from hospitals affiliated to Mashhad University of Medical Sciences. Among 4000 mostly severe cases suspected to be infected that had undergone further investigation, 1278 (32.0\%) were confirmed as true Covid-19 cases by real-time reverse-transcriptasepolymerase-chain-reaction (RT-PCR) assay of nasal and $\backslash$ or pharyngeal swabs. Clinical and demographic results of laboratory-confirmed cases were included in a review of exposure history, health outcomes and 
symptoms. Admission to an intensive care unit (ICU) or the use of mechanical ventilation within this cohort with severe symptoms were the primary end-points of the study. Secondary end-point included duration of hospitalization, history of infection (defined as the time from onset of symptom(s) until discharge from the hospital or death), and outcome (dead or recovered). Fever was defined as axillary temperature $>37.5^{\circ} \mathrm{C}$. Prescribed medications included lopinavir/ritonavir, antibiotics, and oseltamivir. The study tried to generalize the findings for severe Covid-19 cases to avoid selection bias.

\section{Statistics analysis}

Categorical variables were summarized as frequencies and percentages. The Shapiro-Wilk test was used to evaluate normality of data. Normally distributed data were expressed as mean \pm standard deviation (SD), and skewed data as median and interquartile range (IQR). Two-tailed Student's t and Mann-Whitney U tests were used to compare grouped continuous variable data where appropriate. Chi-square and Fisher's exact tests were used to perform intergroup and categorical comparisons as appropriate. Logistic regression was performed to multivariable analysis, comparing deceased and recovered patients. Reported $p$-values of $<0.05$ were considered statistically significant. SPSS software, version 16 (SPSS Inc., Chicago, IL, USA) was used to analyse the data.

This study was approved by the Ethics Committee of the Mashhad University of Medical Science (Ethics code: IR.MUMS.REC.1398.308). We received initial data from the centre for Diseases Prevention and Control of Mashhad University of Medical Sciences and sought missing data from patients' medical records. Thus, we had no plan to contact with patients and the informed consent from patients was not obtained.

\section{Results}

Demographic characteristics

Of the 1278 confirmed Covid-19 patients, 353 (27.6\%)

died and 925 recovered. Mean (SD) age for confirmed patients was 56.9 (18.7) years, for deceased cases 67.1 (15.9) years and for recovered cases 53.0 (18.3) years. There was a statistically significant association between age and mortality with the mortality rate rising with age (Table 1). Multivariable logistic regression analysis also

Table 1 Association between Covid-19 status and outcomes

\begin{tabular}{|c|c|c|c|c|}
\hline \multicolumn{2}{|l|}{ Variable investigated } & \multicolumn{2}{|l|}{$\begin{array}{l}\text { Outcome } \\
\text { Number (\%) }\end{array}$} & \multirow[t]{2}{*}{$P$-value } \\
\hline & & $\begin{array}{l}\text { Deceased } \\
(n=353)\end{array}$ & $\begin{array}{l}\text { Recovered } \\
(n=925)\end{array}$ & \\
\hline \multicolumn{2}{|c|}{ Continuous age - mean (SD) } & $67.1(15.9)$ & $53.0(18.3)$ & $0.0001^{c}$ \\
\hline \multirow[t]{11}{*}{ Age (categorical) } & $0-9$ & $1(0.3)$ & $12(1.3)$ & \multirow[t]{11}{*}{$0.0001^{d}$} \\
\hline & $10-19$ & $1(0.3)$ & $12(1.3)$ & \\
\hline & $20-29$ & $4(1.1)$ & $66(7.1)$ & \\
\hline & $30-39$ & $15(4.2)$ & $130(14.1)$ & \\
\hline & $40-49$ & $25(7.1)$ & $170(18.4)$ & \\
\hline & $50-59$ & $47(13.3)$ & $193(20.9)$ & \\
\hline & $60-69$ & $104(29.5)$ & $165(17.8)$ & \\
\hline & 70-79 & $74(21.0)$ & $102(11.0)$ & \\
\hline & $80-89$ & $62(17.6)$ & $67(7.2)$ & \\
\hline & $90-99$ & $19(5.4)$ & $8(0.9)$ & \\
\hline & $100-109$ & $1(0.3)$ & $0(0.0)$ & \\
\hline \multirow[t]{2}{*}{ Sex } & Female & $129(36.5)$ & $356(38.5)$ & \multirow[t]{2}{*}{$0.52^{\mathrm{d}}$} \\
\hline & Male & $224(63.5)$ & $569(61.5)$ & \\
\hline \multirow[t]{3}{*}{ Therapeutic approach } & Antiviral \& antibiotic & $149(42.2)$ & $401(43.4)$ & \multirow[t]{3}{*}{$0.08^{d}$} \\
\hline & Conservative & $71(20.1)$ & $139(15.0)$ & \\
\hline & Antiviral & $133(37.7)$ & $385(41.6)$ & \\
\hline \multirow[t]{2}{*}{ Specific medication used } & Lopinavir/ritonavir and antibiotic ${ }^{a}$ & $131(37.1)$ & $120(13.0)$ & \multirow[t]{2}{*}{$0.001^{d}$} \\
\hline & Oseltamivir ${ }^{\mathrm{b}}$ & $222(62.9)$ & $805(87.0)$ & \\
\hline \multicolumn{2}{|c|}{ Body temperature $\left(C^{\circ}\right)$ - mean $(S D)$} & $37.6(0.76)$ & $37.7(0.73)$ & $0.09^{c}$ \\
\hline \multicolumn{2}{|c|}{ Hospitalization (days) - median (IQR) } & $9.0(6.0-14.0)$ & $9.0(6.0-14.0)$ & $0.18^{c}$ \\
\hline
\end{tabular}

${ }^{\mathrm{a}}$ prescribed for severe cases; ${ }^{\mathrm{b}}$ prescribed for mild cases; ${ }^{\mathrm{C}}$ Mann-Whitney $\mathrm{U}$ test was used; ${ }^{\mathrm{d}}$ Chi-square test was used 
showed that the outcome of patients was associated with age (odds ratio $=1.049, P=0.0001,95 \% \mathrm{CI}=1.040-$ 1.057), when adjusted for sex, therapeutic approach, body temperature, and duration of hospitalization. Considering age as a categorical variable ( $\leq 50$ vs. $>50$ years), multivariable logistic regression revealed that odds of death among patients $>50$ years was significantly greater than among patients $\leq 50$ years (odds ratio $=4.7 ; 95 \% \mathrm{CI}$, $3.4-6.5 ; P=0.001)$. Despite the high frequency of Covid19 infections accrued in the 30-39 and 40-49 age groups, most of them $(130 / 145=89.6 \%$ and $170 / 195=$ $87.2 \%$, respectively) recovered (Table 1 ; Fig. 1 ). Twentysix $(2.0 \%)$ of all 1.278 confirmed cases were $<20$ years old, and 28 (2.2\%) were $>89$ years (Fig. 1). Most (793/ $1278=62 \%$ ) of the confirmed patients were males, however there was no statistically significant difference in outcomes with reference to sex (Table 1).

\section{Patient end-points}

Of 1278 patients, 151 (11.8\%) were admitted to ICU of which 70 (46.3\%) demised. Furthermore, of 1278 cases, 499 (39.0\%) underwent mechanical ventilation of which 176 (35.3\%) demised (Table 2). The median (IQR) duration of hospitalization was 9.0 (6.0-14.0) days, with no significant difference in duration of hospitalization between those that recovered and those who died (Table 1).

\section{Co-morbidities and symptoms}

The most frequent co-morbidities were cardiovascular disorders (268/1278; 21.0\%) and diabetes (208/1278; 16.3\%). Dyspnoea (929, 72.7\%), cough (870, 68.1\%), and fever $(815,63.8 \%)$ were the most frequent clinical symptoms (Table 2). Overall, 1251/1278 (97.9\%) of the cases had at least one clinical symptom. Compared with survivors, deceased cases showed a higher prevalence of comorbidities including cardiovascular disorders $(28.3 \%$ vs. $18.2 \%)$, diabetes (22.9\% vs. $13.7 \%)$ and chronic respiratory disorders (8.2\% vs. 3.0\%) (Table 2$)$.

\section{Therapeutic approach}

Most patients $(550 / 1278 ; 43 \%)$ received antiviral and antibiotic combination therapy, 518/1278 (40.5\%) received antiviral therapies only, and 210/1278 (16.5\%) did not receive antiviral or antibiotic therapy. No significant differences in the treatment approach between patients that died and those that recovered were observed (Table 1). Mortality rates associated with lopinavir/ritonavir and antibiotic combination therapy and oseltamivir therapy were 37.1 and $62.9 \%$, respectively (Table 1 ).

Of the 1278 confirmed cases, 67 (5.2\%) were healthcare workers, of whom $2(3.0 \%)$ died. The mean (SD) age of affected healthcare workers was 41.5 (11.9) years. Thirty-one (46.3\%) of these healthcare workers were presumed to have been infected through occupational exposure to infected patients. Cough (77.6\%), fever (68.7) and dyspnoea (56.7\%) were the commonest symptoms in healthcare workers with Covid-19. Six (9.0\%) had comorbidities (cardiovascular disorders, $n=3$; diabetes, $n=3)$. Seven $(10.4 \%)$ of the healthcare workers required mechanical ventilation and 6 were admitted to ICU.

\section{Discussion}

This is the first study from Mashhad, Iran, to report the characteristics of patients with severe confirmed Covid19. Increasing age was associated with an increased risk

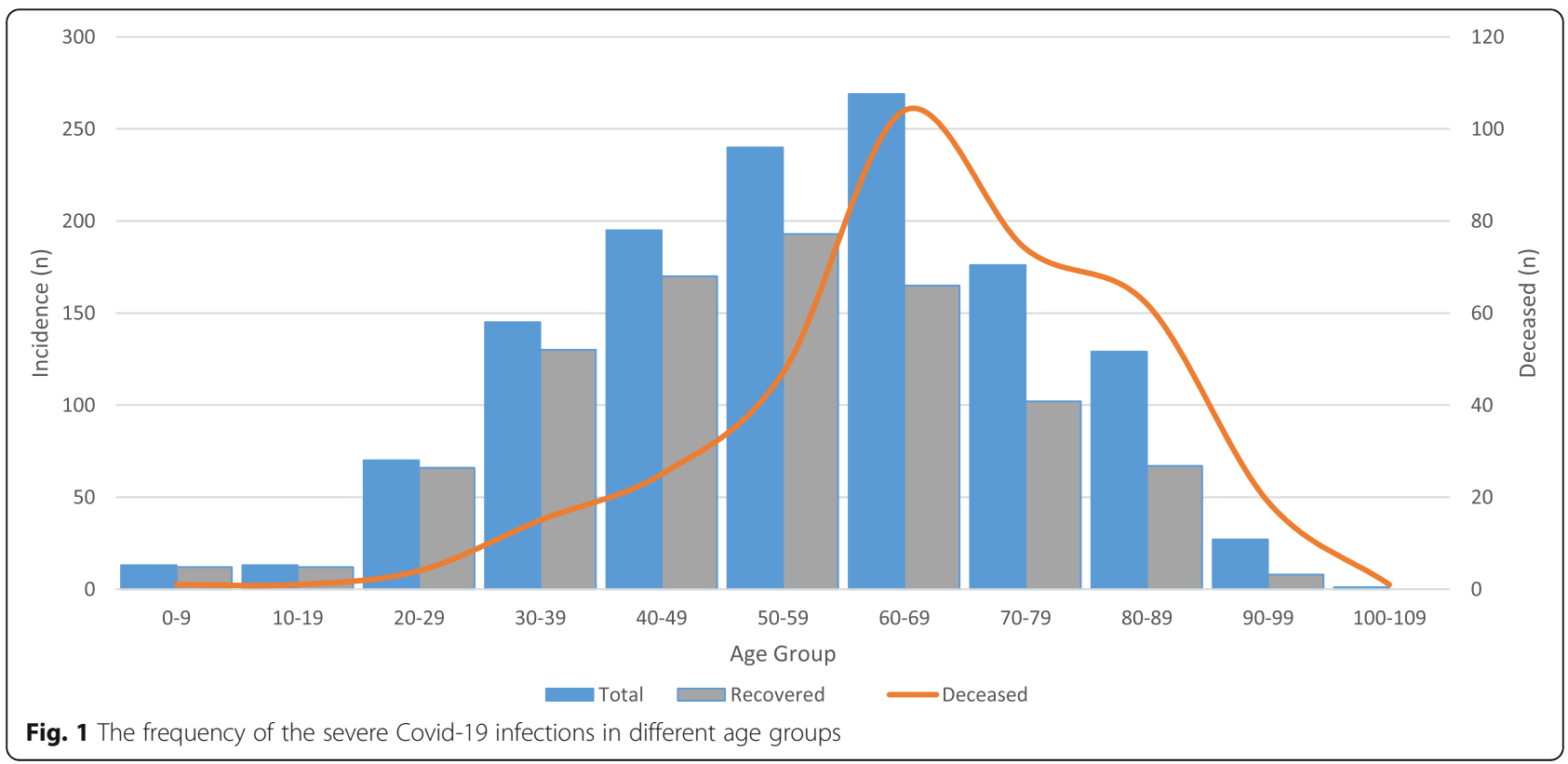


Table 2 Frequency of co-morbidities and symptoms due to COVID-19 infections

\begin{tabular}{|c|c|c|c|}
\hline \multirow{2}{*}{$\begin{array}{l}\text { Frequency } \\
\text { Co-morbidity }\end{array}$} & \multicolumn{3}{|c|}{ Frequency (\%) } \\
\hline & $\begin{array}{l}\text { Among } \\
\text { all } \\
\text { infected } \\
\text { cases } \\
(n= \\
1278)\end{array}$ & $\begin{array}{l}\text { Among } \\
\text { deceased } \\
\text { cases } \\
(n=353)\end{array}$ & $\begin{array}{l}\text { Among } \\
\text { recovered } \\
\text { cases } \\
(n=925)\end{array}$ \\
\hline Cardiovascular disorder & $268(21.0)$ & $100(28.3)$ & $168(18.2)$ \\
\hline Diabetes & $208(16.3)$ & $81(22.9)$ & $127(13.7)$ \\
\hline Hypertension & $172(13.5)$ & $69(19.5)$ & $103(11.1)$ \\
\hline Liver disorders & $45(3.5)$ & $18(5.1)$ & $27(2.9)$ \\
\hline Kidney disorders & $40(3.1)$ & $19(5.4)$ & $21(2.3)$ \\
\hline Chronic resp. disorder & $57(4.5)$ & $29(8.2)$ & $28(3.0)$ \\
\hline Acute resp. distress syndrome (ARDS) & $13(1.02)$ & $4(1.1)$ & $9(0.1)$ \\
\hline Mild pneumonia & $136(10.64)$ & $24(6.8)$ & $112(12.1)$ \\
\hline \multicolumn{4}{|l|}{ Symptom } \\
\hline Fever & $815(63.8)$ & $244(69.1)$ & $571(61.7)$ \\
\hline Cough & $870(68.1)$ & $229(64.9)$ & $641(69.3)$ \\
\hline Dyspnoea & $929(72.7)$ & $287(81.3)$ & $642(69.4)$ \\
\hline General malaise & $247(19.3)$ & $61(17.3)$ & $186(20.1)$ \\
\hline Myalgia & 199 (15.6) & $49(13.9)$ & $150(16.2)$ \\
\hline Confusion & $87(6.8)$ & $41(11.6)$ & $46(5.0)$ \\
\hline Sore throat & $152(11.9)$ & $31(8.8)$ & $121(13.0)$ \\
\hline Diarrhoea & $47(3.7)$ & $11(3.1)$ & $36(3.9)$ \\
\hline Nausea \& vomiting & $113(8.8)$ & $27(7.6)$ & $86(9.3)$ \\
\hline Headache & $114(8.1)$ & $24(6.8)$ & $90(9.7)$ \\
\hline \multicolumn{4}{|l|}{ End-points } \\
\hline ICU admission & $151(11.8)$ & $70(19.8)$ & $81(8.7)$ \\
\hline Using mechanical ventilation & $499(39.0)$ & $176(49.8)$ & $323(34.9)$ \\
\hline \multicolumn{4}{|l|}{ Other } \\
\hline Exposure or visit to hospital within the last 14 days & $131(10.2)$ & $38(10.7)$ & $93(10.0)$ \\
\hline Contact with a respiratory patients in the last 14 days & $616(48.2)$ & $126(35.7)$ & $490(53.0)$ \\
\hline
\end{tabular}

of mortality. The most frequent co-morbidities were cardiovascular disorders and diabetes, and the most frequent symptoms were dyspnoea, cough, and fever. The highest burden of disease clustered in the 50-59 and 60-69 year age groups, while the highest CFR was patients aged $80-89$ years. These findings are in line with previous reports $[5,17,21]$.

Mean (SD) age of Iranian Covid-19 patients in our study was 56.9 (18.7) years, which is similar to other studies [16, 17], but older than that reported by Guan et al. [2] in China who reported a median age (IQR) of 47.0 (35.0-58.0) years, with $55.1 \%$ of their cases between 15 and 49 years, and younger than the median of 64 years reported in other studies [1, 22]. Although most Covid-19 infections in our study occurred in the 50-59 and 60-69 year age groups, the frequency of infection was also considerable in the 3039 and 40-49 year age groups. The high frequency of
Covid-19 infection in these age groups may be due to the low median age (30 years) of the Iranian population and/or due to inclusion of mainly working-age population in this age group [23]. It seems that the frequency of Covid-19 infections rises considerably from the age group of 50-59 years $[24,25]$. In contrast to findings in China and Italy [5, 9], we found a considerably higher proportion of fatalities in the age groups spanning the range from 20 to 50 years. This high proportion of fatalities in young people may be due to differences in life expectancy and age pyramid of different countries [26]. For lower- and middle-income countries, such as Mexico and India, the proportion of deaths among younger age groups appears substantially larger than that in high-income countries such as Canada and the Netherlands. Another reason for this high proportion of fatalities in young people may be due to unknown co- 
morbidities of these people [26]. Elderly people with known co-morbidities may take more care of themselves than young people with unknown co-morbidities. Also, it may be due to shortage of ICU in our setting, which necessitated ventilation of some patients in ordinary wards, i.e. outside of ICU.

In our study, the prevalence of Covid-19 infection was higher among men $(62 \%)$ compared with reports from China (49.3-54.3\%) [16, 22]. However, our finding of male predominance in severe cases was similar to reports from Italy (60\%) [27], and the United States (63\%) [1].

Huang et al. [17] reported a CFR of $15 \%$ among hospitalized Covid-19 cases in China. According to the WHO daily report, the crude CFR was $5.6 \%$ in China by May 10 , 2020. At the beginning of the Covid-19 outbreak in Italy, the crude CFR was $11.8 \%(12,430 / 105,792)$ [28], but this decreased as the number of cases increased. In our study, RT-PCR testing was only used for symptomatic cases, including more severely ill patients at a high risk of mortality. This selection bias, and the fact that our study describes outcomes in confirmed cases during a comparatively short window of time, limits our ability to arrive at accurate estimates of CFR relating Covid-19 in our setting. Long-term screening of all population at risk should facilitate reporting of more reliable CFR estimates in future studies. Estimation of the infection fatality rate (IFR) would also be of interest, but would require reliable antibody detection assays and large population-based samples.

According to WHO interim clinical guidance (Rev. March 20, 2020) [29], fever, cough, fatigue and anorexia are the most common signs of Covid-19 and our findings comply with this. However, in our study dyspnoea (72.7\%) was twice as prevalent compared to WHO estimates (31-40\%) [29]. Prevalence of dyspnoea in our study, was similar to that from United States, however $[1,30]$. The prevalence of dyspnoea in China complies with the WHO guidelines [22, 31, 32], although they may also be slightly higher [33]. The WHO should update the information on symptoms and signs of Covid19 based on new global data, pointing out that there may be differences with respect to region.

Cardiovascular disorders (21\%) and diabetes (16.3\%) were the most prevalent co-morbidities among Covid-19 patients in our study. Previous studies have reported diverse prevalence rates for cardiovascular disorders (11$45 \%)$ and diabetes $(13-35 \%)[1,30,31]$. Meta-analyses report pooled prevalence of 8.4 and $12 \%$ for cardiovascular disorders, and 8.0 to $9.7 \%$ for diabetes [23,33]. Assessing the association between patients' awareness of Covid-19 and risk factors for severe disease and adherence to prevention protocols should be evaluated in future studies [34-38]. Using telehealth-based services during the COVID-19 pandemic may be useful in this regard [39].
The fatality rate among healthcare workers was $3 \%$ in our study, considerably higher than that reported in China $(0.33 \%)$ [40]. This may be due to a shortage of personal protective equipment (PPE) at the early stages of the Covid-19 pandemic in Iran. Future studies should focus on the impact that availability of PPE had on CFR among healthcare workers in Iran, and other countries. Also, performing the appropriate human resource management strategies would increase the safety among healthcare workers [41].

Huang et al. [17] reported that $32 \%$ of patients were admitted to ICU, whereas in our study only $11.8 \%$ received ICU care. The fatality rate among patients treated in ICU was $46.3 \%$ in our study, lower than that $(78 \%)$ reported by Zhou et al. [5]. All patients admitted to ICU received broad-spectrum antibiotics and antiviral medications, a combination that may have contributed to the lower mortality rate in our setting. Importantly, the use of RT-PCR testing in all ICU-admitted patients strengthened the reliability of CFR estimates of this category of patients.

To our knowledge, this is the first study to address the characteristics of Covid-19 patients confirmed by RT-PCR in Mashhad, Iran. However, it has limitations, chiefly in that the RT-PCR testing approach focused on cases with severe symptoms, most of which were hospitalized. We analysed data from patients treated in facilities served by the Mashhad University of Medical Sciences, and so did not cover all areas of Razavi Khorasan, although most patients requiring hospitalization are routinely referred to this city. Despite the above-mentioned limitations, we feel that our findings are instructive and will inform future research, both in Iran and internationally.

\section{Conclusions}

In summary, the frequency of Covid-19 fatalities rose considerably from 30 to 39 years, with a higher number of fatalities in younger patients than in international studies. Fever, cough, and dyspnoea were common symptoms among hospitalized patients with Covid-19. Diabetes and cardiovascular disorders were the most prevalent co-morbidities, as observed in other studies.

\section{Abbreviations \\ Covid-19: Coronavirus Disease 2019; SARS-CoV-2: Severe acute respiratory syndrome coronavirus 2; SARS: Severe acute respiratory syndrome; \\ ICU: Intensive care unit; RT-PCR: Real-time reverse-transcriptase polymerase chain reaction}

\section{Supplementary Information}

The online version contains supplementary material available at https://doi. org/10.1186/s12879-021-06363-6.

Additional file 1. STROBE Statement-Checklist of items that should be included in reports of cross-sectional studies. 


\section{Acknowledgments}

We would like to thank all personnel of Mashhad University of Medical Sciences for their supports. This version of the manuscript has been posted on the medRxiv server of preprints [42].

The members of MUMS Covid-19 Research Team:

Nasrin Milani', Mahdi Gholian-Aval ${ }^{2}$, Fariba Rezaeitalab ${ }^{3}$, Mohammad Jafar Sadeghi Quchani ${ }^{4}$, Zahra Nahbandani ${ }^{4}$, Mandana Khodashahi ${ }^{5}$, Zahra Javid ${ }^{3}$, Mahnaz Mozdourian', Mohammad Ali Yaghoubi ${ }^{6}$, Zahra Mozaheb ${ }^{7}$, Mohsen Seddigh-Shamsi ${ }^{7}$, Mohammad Moeini Nodeh ${ }^{7}$, Shima Nabavi ${ }^{1}$, Hooman Mosannen Mozaffari ${ }^{8}$, Mohammadreza Farzanehfar ${ }^{8}$, Zahra Lotfi ${ }^{1}$, Alireza Shariati $^{1}$, Shekoofe Bonakdaran ${ }^{6}$, Zahra Rezaieyazdi ${ }^{6}$, Zahra Mirfeizi ${ }^{5}$, Maryam Miri ${ }^{9}$, Reza Bassiri ${ }^{3}$, Sajjad Ataei Azimi ${ }^{7}$

'Department of internal medicine, Mashhad University of Medical Sciences, Mashhad, Iran.

${ }^{2}$ Department of Health education \& Health promotion, Social determinants of health research center, School of health, Mashhad University of Medical Sciences, Mashhad, Iran.

${ }^{3}$ Lung Disease Research Center, Mashhad University of Medical Sciences, Mashhad, Iran.

${ }^{4}$ Department of health, Social determinants of health research center, Mashhad University of Medical Sciences, Mashhad, Iran.

${ }^{5}$ Rheumatic Diseases Research Center, Mashhad University of Medical Sciences, Mashhad, Iran.

${ }^{6}$ Metabolic syndrome research center, Mashhad University of Medical Sciences, Mashhad, Iran.

${ }^{7}$ Department of Hematology \& Oncology, Faculty of Medicine, Mashhad University of Medical Sciences, Mashhad, Iran.

${ }^{8}$ Department of Gastroenterology and Hepatology, Faculty of Medicine,

Mashhad University of Medical Sciences, Mashhad, Iran.

${ }^{9}$ Kidney transplantation complications research center, Mashhad University of Medical Sciences, Mashhad, Iran.

\section{Authors' contributions}

$\mathrm{BH}, \mathrm{RB}, \mathrm{AA}$ designed the study design. All authors contributed in data gathering and interpretation of the results. $L G, M A R, B H, K H$ wrote the first draft of the manuscript. RB edited final version of the manuscript. All authors read, commented and approved the final manuscript. The members of the MUMS Covid-19 Research Team collaborated in data gathering.

\section{Funding}

This work was supported by Mashhad University of Medical Sciences (grant number of 981800). The funder had no role in the design of the study and collection, analysis, and interpretation of data and in writing the manuscript.

\section{Availability of data and materials}

The datasets used and/or analysed during the current study are available from the corresponding author on reasonable request.

\section{Declarations}

Ethics approval and consent to participate

This study was approved by the Ethics Committee of the Mashhad University of Medical Science (Ethics code: IR.MUMS.REC.1398.308).

\section{Consent for publication}

Not applicable.

\section{Competing interests}

The authors declare that they have no competing interests.

\section{Author details}

'Department of Gastroenterology and Hepatology, Faculty of Medicine, Mashhad University of Medical Sciences, Mashhad, Iran. ${ }^{2}$ Surgical Oncology Research Center, Mashhad University of Medical Sciences, Mashhad, Iran. ${ }^{3}$ Department of Internal Medicine, Mashhad University of Medical Sciences, Mashhad, Iran. ${ }^{4}$ Ingerod, SE-454 94 Brastad, Sweden. ${ }^{5}$ Formerly UNICEF/ UNDP/World Bank/WHO Special Programme for Research and Training in Tropical Diseases (TDR), World Health Organization, Geneva, Switzerland. ${ }^{6}$ Rheumatic Diseases Research Center, Mashhad University of Medical Sciences, Mashhad, Iran. ${ }^{7}$ Department of Health Information Technology,
Neyshabur University of Medical Sciences, Neyshabur, Iran. ${ }^{8}$ Pharmaceutical Research Center, Mashhad University of Medical Sciences, Mashhad, Iran.

Received: 27 May 2020 Accepted: 28 June 2021

Published online: 07 July 2021

\section{References}

1. Bhatraju PK, Ghassemieh BJ, Nichols M, Kim R, Jerome KR, Nalla AK, et al. Covid-19 in critically ill patients in the Seattle region - case series. N Engl Med. 2020;382(21):2012-22. https://doi.org/10.1056/NEJMoa2004500 PubMed PMID: 32227758.

2. Guan W-J, Ni Z-Y, Hu Y, et al. Clinical characteristics of coronavirus disease 2019 in China. N Engl J Med. 2020;382(18):1708-20.

3. Munster VJ, Koopmans M, van Doremalen N, van Riel D, de Wit E. A novel coronavirus emerging in China - key questions for impact assessment. N Engl J Med. 2020;382(8):692-4. https://doi.org/10.1056/NEJMp2000929 Epub 2020/01/25. PubMed PMID: 31978293

4. Zhang L, Shen FM, Chen F, et al. Origin and Evolution of the 2019 Novel Coronavirus. Clin Infect Dis. 2020;71(15):882-3. https://doi.org/10.1093/cid/ ciaa112 PubMed PMID: 32011673; PubMed Central PMCID: PMCPmc7108176.

5. Zhou F, Yu T, Du R, et al. Clinical course and risk factors for mortality of adult inpatients with COVID-19 in Wuhan, China: a retrospective cohort study. Lancet. 2020;395(10229):1054-62. https://doi.org/10.1016/s0140-673 6(20)30566-3 Epub 2020/03/15. PubMed PMID: 32171076.

6. Ghinai I, MCPherson TD, Hunter JC, et al. First known person-to-person transmission of severe acute respiratory syndrome coronavirus 2 (SARS-CoV2) in the USA. Lancet. 2020;395(10230):1137-44. https://doi.org/10.1016/s014 0-6736(20)30607-3 Epub 2020/03/18. PubMed PMID: 32178768; PubMed Central PMCID: PMCPmc7158585

7. Jin Y, Yang H, Ji W, et al. Virology, Epidemiology, Pathogenesis, and Control of COVID-19. Viruses. 2020;12(4):372. https://doi.org/10.3390/N12040372.

8. McMichael TM, Currie DW, Clark S, et al. Epidemiology of Covid-19 in a long-term care facility in King County, Washington. N Engl J Med. 2020; 382(21):2005-11. https://doi.org/10.1056/NEJMoa2005412 Epub 2020/03/29. PubMed PMID: 32220208; PubMed Central PMCID: PMCPmc7121761.

9. Zhou $P$, Yang $X-L$, Wang $X-G$, Hu B, Zhang $L$, Zhang W, et al. A pneumonia outbreak associated with a new coronavirus of probable bat origin. Nature. 2020;579(7798):270-3. https://doi.org/10.1038/s41586-020-2012-7.

10. Bergquist R, Kiani B, Manda S. First year with COVID-19: Assessment and prospects. Geospatial health. 2020;15(2). https://doi.org/10.4081/gh.2020.953 Epub 2021/01/20. PubMed PMID: 33461262.

11. Mahase E. China coronavirus: what do we know so far? BMJ. 2020;368:m308. https://doi.org/10.1136/bmj.m308 Epub 2020/01/26. PubMed PMID: 31980434

12. WHO, 2019 Middle East respiratory syndrome coronavirus (MERS-Cov). 2019. Available from: https://www.who.int/emergencies/merscov/en/.

13. Zou L, Ruan F, Huang M, et al. SARS-CoV-2 viral load in upper respiratory specimens of infected patients. N Engl J Med. 2020;382(12):1177-9. https:// doi.org/10.1056/NEJMc2001737 Epub 2020/02/20. PubMed PMID: 32074444; PubMed Central PMCID: PMCPmc7121626.

14. Goshayeshi L, Milani N, Bergquist R, et al. Covid-19 presented only with gastrointestinal symptoms: a case report of a 14-year-old patient. Govaresh. 2021;25(4):300-304. http://govaresh.org/index.php/dd/article/view/2341.

15. Goshayeshi L, Milani N, Bergquist R, et al. Covid-19 only with gastrointestinal (GI) symptoms: case report of a 14-year-old patient. 2020. https://www.resea rchsquare.com/article/rs-27389/v4. https://doi.org/10.21203/rs.3.rs-27389/v4.

16. Wang D, Hu B, Hu C, et al. Clinical characteristics of 138 hospitalized patients with 2019 Novel Coronavirus-Infected Pneumonia in Wuhan, China. JAMA. 2020;323(11):1061-9. https://doi.org/10.1001/jama.2020.1585 Epub 2020/02/08. PubMed PMID: 32031570; PubMed Central PMCID: PMCPmc7042881.

17. Huang C, Wang Y, Li X, Ren L, Zhao J, Hu Y, et al. Clinical features of patients infected with 2019 novel coronavirus in Wuhan, China. Lancet. 2020;395(10223):497-506. https://doi.org/10.1016/S0140-6736(20)30183-5.

18. Khodashahi R, Naderi $H$, Bojdy A, et al. Comparison the effect of arbidol plus hydroxychloroquine vs hydroxychloroquine alone in treatment of COVID-19 disease: a randomized clinical trial. Curr Respir Med Rev. 2020;16(4):252-62. https://doi.org/10.2174/1573398X17666210129125703.

19. Khodashahi R, Naderi HR, Sedaghat A, Allahyari A, Sarjamee S, et al. Intravenous Immunoglobulin for Treatment of Patients with COVID-19: A 
Case-control Study, Arch Clin Infect Dis. 2021;16(1):e108068. https://doi.org/1 0.5812/archcid. 108068 .

20. Wu Z, McGoogan JM. Characteristics of and important lessons from the coronavirus disease 2019 (COVID-19) outbreak in China: summary of a report of 72314 cases from the Chinese Center for Disease Control and Prevention. JAMA. 2020;323(13):1239-42. https://doi.org/10.1001/jama.2020.2 648 Epub 2020/02/25. PubMed PMID: 32091533.

21. Su Z, McDonnell D, Cheshmehzangi A, et al. The promise and perils of Unit 731 data to advance COVID-19 research. BMJ Global Health. 2021;6(5). https://doi.org/10.1136/bmjgh-2020-004772 Epub 2021/05/22. PubMed PMID: 34016575; PubMed Central PMCID: PMCPMC8141376.

22. Shi S, Qin M, Shen B, et al. Association of cardiac injury with mortality in hospitalized patients with COVID-19 in Wuhan, China. JAMA Cardiol. 2020; 5(7):802-10. https://doi.org/10.1001/jamacardio.2020.0950 Epub 2020/03/27. PubMed PMID: 32211816; PubMed Central PMCID: PMCPmc7097841.

23. Emami A, Javanmardi F, Pirbonyeh $\mathrm{N}$, et al. Prevalence of underlying diseases in hospitalized patients with COVID-19: a systematic review and meta-analysis. Arch Acad Emerg Med. 2020;8(1):e35 Epub 2020/04/02. PubMed PMID: 32232218; PubMed Central PMCID: PMCPmc7096724.

24. Bergquist R, Rinaldi L. Covid-19: Pandemonium in our time. Geospatial health. 2020;15(1). https://doi.org/10.4081/gh.2020.880 Epub 2020/04/03. PubMed PMID: 32238978

25. Bergquist R, Stengaard AS. Covid-19: End of the beginning? Geospatial Health. 2020;15(1). https://doi.org/10.4081/gh.2020.897 Epub 2020/06/25 PubMed PMID: 32575955.

26. Ioannidis JPA, Axfors C, Contopoulos-loannidis DG. Population-level COVID19 mortality risk for non-elderly individuals overall and for non-elderly individuals without underlying diseases in pandemic epicenters. Environ Res. 2020;188:109890. https://doi.org/10.1016/j.envres.2020.109890 Epub 2020/08/28. PubMed PMID: 32846654; PubMed Central PMCID: PMCP MC7327471

27. Grasselli G, Zangrillo A, Zanella A, et al. Baseline characteristics and outcomes of 1591 patients infected with SARS-CoV-2 admitted to ICUs of the Lombardy Region, Italy. JAMA. 2020;323(16):1574-81. https://doi.org/10.1 001/jama.2020.5394 Epub 2020/04/07. PubMed PMID: 32250385; PubMed Central PMCID: PMCPMC7136855.

28. Lippi G, Mattiuzzi C, Sanchis-Gomar F, et al. Clinical and demographic characteristics of patients dying from COVID-19 in Italy vs China. J Med Virol. 2020;92(10):1759-60. https://doi.org/10.1002/jmv.25860 Epub 2020/04/ 11. PubMed PMID: 32275075; PubMed Central PMCID: PMCPmc7262193.

29. WHO. Interim clinical guidance for management of patients with confirmed coronavirus disease (COVID-19) 2020 [cited 2020 March 20]. Available from: https://www.cdc.gov/coronavirus/2019-ncov/hcp/clinical-guidance-mana gement-patients.html.

30. Arentz $\mathrm{M}$, Yim E, Klaff $\mathrm{L}$, et al. Characteristics and outcomes of 21 critically ill patients with COVID-19 in Washington State. JAMA. 2020;323(16):1612-4. https://doi.org/10.1001/jama.2020.4326 Epub 2020/03/20. PubMed PMID: 32191259; PubMed Central PMCID: PMCPmc7082763.

31. Xiao K, Zhai J, Feng Y, Zhou N, Zhang X, Zou JJ, et al. Isolation of SARS-CoV2-related coronavirus from Malayan pangolins. Nature. 2020;583(7815):2869. https://doi.org/10.1038/s41586-020-2313-x.

32. Xu X, Yu C, Qu J, et al. Imaging and clinical features of patients with 2019 novel coronavirus SARS-CoV-2. Eur J Nuclear Med Mol Imaging. 2020:47(5): 1275-80. https://doi.org/10.1007/s00259-020-04735-9 Epub 2020/02/29. PubMed PMID: 32107577; PubMed Central PMCID: PMCPMC7080117.

33. Yang $X, Y u Y, X u$ J, et al. Clinical course and outcomes of critically ill patients with SARS-CoV-2 pneumonia in Wuhan, China: a single-centered, retrospective, observational study. Lancet Respir Med. 2020;8(5):475-81. https://doi.org/10.1016/s2213-2600(20)30079-5 Epub 2020/02/28. PubMed PMID: 32105632; PubMed Central PMCID: PMCPmc7102538

34. Su Z, McDonnell D, Wen J, et al. Mental health consequences of COVID-19 media coverage: the need for effective crisis communication practices. Global health. 2021;17(1):4. https://doi.org/10.1186/s12992-020-00654-4 Epub 2021/01/07. PubMed PMID: 33402169; PubMed Central PMCID: PMCP MC7784222.

35. Shuja KH, Aqeel M, Jaffar A, et al. COVID-19 pandemic and impending global mental health implications. Psychiatria Danubina. 2020;32(1):32-5. https://doi.org/10.24869/psyd.2020.32 Epub 2020/04/18. PubMed PMID: 32303027

36. Yoosefi Lebni J, Abbas J, Moradi F, et al. How the COVID-19 pandemic effected economic, social, political, and cultural factors: A lesson from Iran.
Int J Soc Psychiatry. 2021;67(3):298-300. https://doi.org/10.1177/002076402 0939984 Epub 2020/07/04. PubMed PMID: 32615838; PubMed Central PMC D: PMCPMC8107447.

37. NeJhaddadgar N, Ziapour A, Zakkipour G, et al. Effectiveness of telephonebased screening and triage during COVID-19 outbreak in the promoted primary healthcare system: a case study in Ardabil province, Iran. J Public Health. 2020:1-6. https://doi.org/10.1007/s10389-020-01407-8 Epub 2020/11/ 24. PubMed PMID: 33224715; PubMed Central PMCID: PMCPMC7665795.

38. Abbas J, Wang D, Su Z, et al. The role of social media in the advent of COVID-19 pandemic: crisis management, mental health challenges and implications. Risk Manag Healthc Policy. 2021;14:1917-32. https://doi.org/1 0.2147/rmhp.s284313 Epub 2021/05/21. PubMed PMID: 34012304; PubMed Central PMCID: PMCPMC8126999.

39. Khoshrounejad F, Hamednia M, Mehrjerd A, et al. Telehealth-based services during the COVID-19 pandemic: a systematic review of features and challenges. Front Public Health. 2021;9(844). https://doi.org/10.3389/fpubh.2 021.711762.

40. Xiang YT, Jin Y, Wang Y, et al. Tribute to health workers in China: A group of respectable population during the outbreak of the COVID-19. Int J Biol Sci. 2020;16(10):1739-40. https://doi.org/10.7150/ijbs.45135 Epub 2020/04/ 01. PubMed PMID: 32226292; PubMed Central PMCID: PMCPMC7098026.

41. Azizi MR, Atlasi R, Ziapour A, et al. Innovative human resource management strategies during the COVID-19 pandemic: A systematic narrative review approach. Heliyon. 2021;7(6):e07233. https://doi.org/10.1016/j.heliyon.2021. e07233 Epub 2021/06/15. PubMed PMID: 34124399; PubMed Central PMCID: PMCPMC8183111.

42. Goshayeshi L, Rad MA, Bergquist R, et al. Demographic and Clinical Characteristics of the Severe Covid-19 Infections: First Report from Mashhad University of Medical Sciences, Iran. medRxiv. 2020:2020.05.20.20108068. https://doi.org/10.1101/2020.05.20.20108068.

\section{Publisher's Note}

Springer Nature remains neutral with regard to jurisdictional claims in published maps and institutional affiliations.

Ready to submit your research? Choose BMC and benefit from:

- fast, convenient online submission

- thorough peer review by experienced researchers in your field

- rapid publication on acceptance

- support for research data, including large and complex data types

- gold Open Access which fosters wider collaboration and increased citations

- maximum visibility for your research: over $100 \mathrm{M}$ website views per year

At BMC, research is always in progress.

Learn more biomedcentral.com/submissions 